\title{
Contributions to Eco-design of Machine-to-Machine Product Service Systems: the example of Waste Glass Collection
}

\author{
Alan Lelah, Fabrice Mathieux, Daniel Brissaud \\ Laboratoire G-SCOP - University of Grenoble, 46 avenue Félix Viallet, F-38031 Grenoble Cedex 1, France \\ Email: alan.lelah@g-scop.inpg.fr ; Phone: +33 476574893 \\ Article to be published in Journal of Cleaner Production
}

DOI 10.1016/j.jclepro.2011.02.003

\begin{abstract}
Efficient waste management is necessary in order to face up to increasing quantities of waste generated in modern societies. A technical solution using a Machine-to-Machine (M2M) enhanced Product-Service System (PSS) for bring-in waste glass collection is identified. Methodology based on Life Cycle Analysis (LCA) is proposed. The results help understand the mechanisms of M2M PSS. Possible improvements are explored and the study shows how the PSS infrastructure impacts the environment. It examines the influence of major organisational parameters and contributes to eco-design and dimensioning of the M2M PSS. It reveals the interest of mutualisation to reduce environmental impacts and shows the importance of limiting data exchanges. It argues for the use of multi-criteria LCA on the complete system including the telecom infrastructures and employs realistic use scenarios derived from field studies.
\end{abstract}

\section{Keywords}

product-service system; eco-design; waste management; machine-to-machine; life cycle analysis

\section{Introduction}

Today's society of consumption faces important ecological issues with an increasing and urgent need for efficient waste management systems. Various design strategies that limit waste production, applicable to products and systems, are currently developed: Design for Recycling (Kriwet et al., 1995), for Reuse (Lo, 1998), for Remanufacturing (Ijomah et al., 2007). These strategies are all very promising but unfortunately are not sufficient to drastically invert current trends of increasing quantities of waste generated in modern cities. Indeed, more efficient collection and management of waste is still needed, in particular in Europe.The European Council (2008) has called waste "any substance or object which the holder discards or intends or is required to discard" and defined the terms of "waste management" covering topics such as responsibility, disposal, recovery and recycling. Seadon (2010) pointed that waste management was a complex system. The move to a more sustainable society and waste management system implied greater sophistication and required the identification and application of leverage points to effect change (Seadon, 2010). Waste glass collection for recycling is visible in most European towns today. The European Glass Container Federation (FEVE, 2008) indicated recycling rates for glass attaining $61 \%$ in France and $65 \%$ in the rest of Europe, while the French Agency for the Environment and Energy (ADMEME, 2006) showed that $38 \%$ of materials used in total glass production in France were derived from cullet. Household waste glass collection for recycling had started in France in 1974 and quickly spread to the whole territory (DCCSVMF, 2010). In the 90's, bring-in systems for waste glass were organized and bottle banks were generalized in France (Bouzon, 2005).

Previous authors studied waste collection systems using Life Cycle Analysis (LCA). Bovea et al. (2009) assessed different alternative management scenarios from an environmental perspective. They showed that recycling had the potential to reduce pollution by avoiding the consumption of virgin material. Edwards and Schelling (1999) had proposed a model to study collection of waste and applied it to glass. They estimated the distances travelled by consumers bringing the waste glass to collection sites; vehicles collecting cullet from these sites for delivery to transfer stations (local transport) and long distance haulage from the transfer stations to the glass production plant. They found that fuel consumption was constant for practical recycling rates, but even for low density and hence low recycling site densities, its impact did not exceed recycling benefits. They estimated that energy savings from recycling glass reached a maximum of $4 \mathrm{MJ}$ per $\mathrm{kg}$ of produced glass at a recovery rate of $83 \%$. González-Torre et al. (2003) proposed that in order to improve collection of waste glass, efforts were necessary to increase the number of collection points, dispersing them and locating them in populated centres. The high relevance of supply chain and logistics issues was confirmed by literature in other areas such as bio-energy production systems (Gold and Seuring, 2011). Bjarnadottir et al. (2002) laid the guidelines for the use of LCA in waste management systems. 
LCA would be applied in order to compare the environmental performance of alternative waste treatment systems and identify focus areas for system performance improvement. It would also help to improve eco-design and introduce regulations that promote better alternatives.

More recently, monitoring systems based on sensor technologies were reported. Rovetta et al. (2009) installed monitoring systems on private bins, but environmental impacts were not considered and large scale implementation would require significant reductions of cost and size. Johansson (2006) showed that dynamic scheduling using sensors should lower operating cost and reduced collection and hauling distances, and therefore environmental impacts. However, the sensors measured only threshold glass-levels and did not allow continuous monitoring.

In conclusion, literature on waste collection clearly showed environmental interest in systems that improve the collection of waste glass with bring-in points. It stressed on the need for higher densities of collection points to encourage disposal behaviour. The use of new technologies to reduce transport during local collection could facilitate the installation of supplementary collection points without increasing fuel consumption.

This paper examines the environmental consequences of one possible solution built in the perspective of Product-Service Systems (PSS) using Machine-to-Machine (M2M) technologies. It seeks to improve the collection of waste glass and reduce transport of the cullet. The results are used to orient eco-design of the system towards structural solutions displaying lower environmental impacts.

Whatever improvements may be gained in collection transport, it is necessary to verify that the impact of the M2M equipment itself would not outbalance them. Moreover, as M2M technologies are still rather recent, knowledge of environmental performances in early development phases could also contribute to more environmentally conscious M2M systems in the future. This paper uses methodology based on LCA to test some new concepts that potentially open possibilities for ecodesign of the system as a whole. It does not intend to undertake an extensive eco-design of the system, but rather to propose methodology capable of examining environmentally interesting concepts. The concepts could then be generalised and contribute to the environmental assessment and eco-design of M2M technologies and, more generally, Information and Communication Technologies (ICT) and of M2M-enhanced PSS (M2M PSS).

The paper is organized in five sections. Following the introduction the M2M PSS solution for waste glass collection is presented in section 2. It includes a brief explanation of PSS and M2M principals and then outlines the different elements used in the M2M PSS. The next section proposes to use LCA methodology in an eco-design perspective for M2M PSS applications. Section 4 presents a case study of a conventional waste-collection scenario and the proposed M2M PSS solution. LCA is carried out and the important contributors to environmental impacts are identified and discussed. The environmental benefits associated with the service and the influence of design parameters, including the opportunity of a mutualised infrastructure and the choice of data rates, resulting in eco-design proposals for the PSS considered as a system, are then discussed in section 5 . The final section concludes the case study and the methodology.

\section{An M2M PSS Solution for Waste Glass Collection}

\subsection{Machine to Machine Technology}

ICT has become one of the most dominating factors in modern evolution, radically modifying the way we live and work, resulting in many new usages (Nakamura et al., 2006). The scope of telecommunications expanded from humans to objects, and smart objects started to communicate. Equipped with sensors or actuators, they become sensible machines interacting with their environment. Sensible machines form networks communicating with other machines. This is called M2M communication (Bonneau, 2005, Lawton, 2004). M2M techniques find use in many areas from banking to health, agriculture and industry, just to name a few. Organized M2M networks collect information regarding the state of machines and push it on to other machines that could be located further away. In this way central computers gather information from different sources and make decisions on the operation of widely spread-out systems. Then they send back instructions to machines that respond to changing situations automatically. They also share information with humanbeings who could intervene more efficiently when necessary. ICT techniques such as M2M using sensors to measure the glass levels in the waste bins are a candidate for improving waste glass collection. Real-time information regarding the level of cullet in the disposal bins can help the waste collection services. It would keep them informed which bins have to be emptied at the right time and contribute to optimizing the collection rounds. With an M2M network the services are constantly informed of the state of the bins and can therefore ensure a more efficient service.

A business proposal for waste glass collection using M2M can be imagined. The M2M provider would 
sell the necessary M2M products directly to the local council. The technical services of the local council would be formed to install, run and maintain the M2M equipment. They would interpret the data and decide the best way to collect the cullet. They could also buy optimization software to assist them but would probably have to adapt it to suit their particular needs. The staff would keep in touch with newer more efficient products or norms that come out to the market in the rapidly evolving, highly technical domain of M2M. Software would eventually need updating, new services would eventually become available and this might become a problem for many local councils. Although this model is possible it would pose problems that local services would probably prefer not to assume. In addition other evolutions such as building mutualised infrastructures or optimizing data rates that provide important environmental advantages, as shown in section 5 , are clearly beyond the competencies of the local council. The environmental setbacks of non-expert management are difficult to quantify and this model is not adapted in an eco-design perspective of the system.

\subsection{Product-Service Systems}

PSS (Goedkoop et al., 1999, Baines et al., 2007) replaced the traditional view on products as the reason for sale by marketable services based on underlying products jointly produced by the provider and the customer. Tukker (2004) proposed an 8-level grid for PSS to analyse practice, placing them on a scale moving from pure products to pure services. The grid included product related services; advice and consultancy; product lease; product renting/sharing; product pooling; activity management; pay per service unit; and finally functional results. Sustainability was often found in the heart of preoccupations (Mont, 2002) and many authors saw PSS as a chance to obtain the famous factor 4 or 20 for the environment (McAloone and Andreasen, 2002). Tukker (2004) pointed out that PSSs could result in lower impacts than products by their inherent design, or by stimulating user and provider behaviour geared towards low material and energy use. However, he showed that a win-win situation was not automatically true. Maussang et al. (2009) showed the importance of assessing and evaluating the dispositive from the early design phases. They said that physical objects and service units related to each other and that designers had to carefully consider the interactions between those elements. They concluded that scenario description was interesting to describe both actions between the system and the user (in the case of use) and actions within the system between the elements. Considering services in general, Bartolomeo et al. (2003) identified three types of eco-efficient services: product-based services; electronic substitution services and information-based services. Carrillo-Hermosilla et al. (2010) studied the diversity of eco-innovations according to different dimensions: design; user; product service and governance. They concluded that all these dimensions played a significant role in the management of eco-innovation.

A PSS using M2M technology can be a good solution to overcome the difficulties faced by the local councils in the product sale solution described in 2.1. The PSS would use the M2M techniques with the sensors that measure the glass-levels. As in the product sale solution data would be sent through telecommunication networks. However additional services could also be added on with an M2M platform. Dedicated servers would collect the information and directly provide services to the local councils.

\subsection{Elements of the M2M PSS}

Tukker and Tischner (2006) said that "PSS consists of a mix of tangible products and intangible services designed and combined so that they jointly are capable of fulfilling final customer needs". The elements constituting the M2M PSS solution for waste glass collection are shown in figure 1. The solution provides intangible services through a set of physical products. The lower part of the figure displays the elements that are traditionally owned and run by local waste management services. The final user is the town resident who disposes waste glass in collection bins provided to that effect. Collection trucks are used to empty the bins and require fuel to run. The local services require a computer to access information provided by the PSS provider. The local technical services undertake the collection rounds and manage the bottle bank park. The local authorities are in contact with the final users that are the residents of the town.

The M2M PSS provider owns the tangible products and provides services. Operation will be more deeply explained in section 4, but basically the products consist of sensors to measure the glass levels in the containers; communication modules to relay the collected data; gateways to connect the equipment with the global telecom infrastructure (strictly speaking this is not the property of the PSS provider but it has been included here to simplify the figure); and finally servers to house software applications. The major interests in the M2M PSS solution are the services provided by the PSS. The PSS provider will take care of the optimization of the collection rounds. The local council will benefit from real-time information regarding the park of bins and a planning adapted to the truck-drivers' 
needs. Other services include technical services like installation, maintenance, operation and upgrading of the network of sensors and their corresponding communication modules and gateways. These technical services are facilitated by the M2M platform. The outcome expected from the M2M PSS is that glass collection will be more efficient with fewer nuisances and lower environmental consequences due to the reduction of needs of physical products. It must fulfil the final users', or in other words, the residents', needs. Section 5 will deal with these issues.

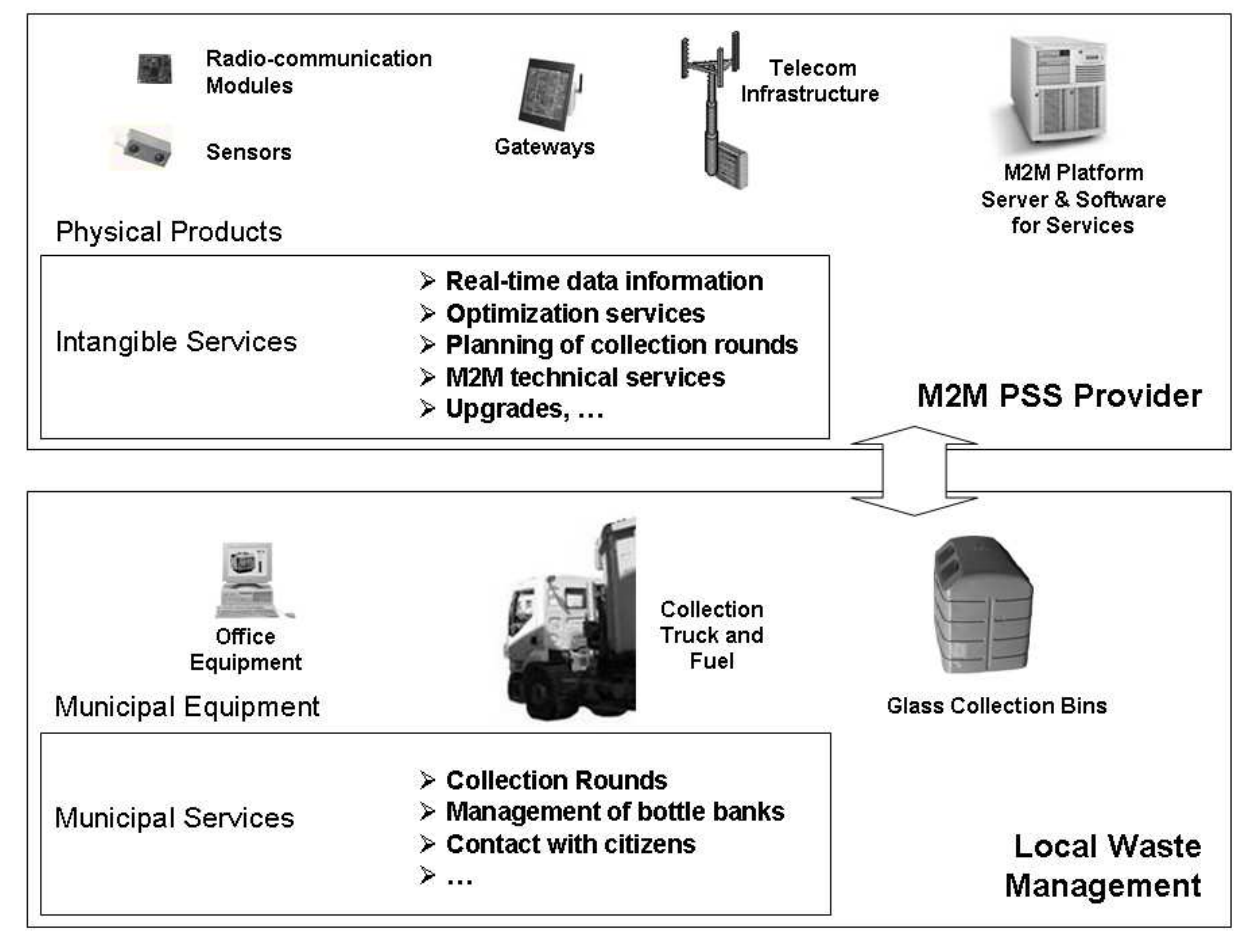

Figure 1: Tangible Products and Intangible Services of the M2M PSS

\section{Issues for the Eco-Design of M2M PSS}

The objective of the case study undertaken in this paper is to identify and underline critical issues concerning the eco-design of the M2M PSS application. The starting point is a life cycle assessment of the system and its elements. This paper seeks to go beyond simple LCA that identifies environmental hot-spots concerning the design of individual equipment involved in the system and obtain results on global parameters capable of influencing the very structure of the M2M PSS, considered as a system running under certain conditions or scenarios. The paper does not search for extensive eco-design of the system, but rather shows how the methodology can open out new and important prospects for eco-design. The LCA methodology must first meet with the requirements of ISO 14040 and 14044 guidelines. However, in view of the complexity of the system studied, additional emphasis must be placed on certain points. This section first studies current trends in ICT evaluation and then puts the accent on important issues that must be stressed in the case of M2M PSS.

\subsection{LCA and ICT}

As we saw, M2M technology could provide very promising solutions for PSS. However the ICTs could display positive, negative or neutral impacts on the environment and are greatly dependant on human behaviour and rebound effects (Plepys, 2002). The electronic industry is very demanding on natural resources. Considering PSS, Tasaki et al. (2006) compared leasing to conventional reuse of electronic and electric equipment, clarifying the conditions by which leasing would use less materials. Generally, LCA is considered a good tool to evaluate environmental impacts for products or systems (Dubberley et al., 2004, Pennington et al., 2004). Authors had already used LCA for ICT services, however most work used only one environmental criterion such as energy consumption (Taiariol et al., 2001, Moberg et al., 2010) or global warming potential (Loerincik et al., 2003, Takahashi et al., 2004). Dubberley et al. (2004) adopted a multi-criteria approach on an intelligent lighting service showing lesser impact than the conventional system for nine environmental impact categories. Loerincik et al. (2003) proposed to use the input-output method for ICT services. The importance of the use phase in ICT was identified by Taiariol et al. (2001). Most of the studies compared alternative scenarios. Reap et al. (2008) warned that "inherent difficulty with any formal scenario analysis framework is that of 
trying to predict with confidence the future." The choice of scenarios would be very important. One common point in the different ICT studies was that in order to apply LCA methodology, they divided the service into elementary parts. In this way, LCA was first applied to individual electronic devices and the result for the complete service was obtained by summing up individual impacts. However, none of these studies took into account service infrastructure; neither did they clearly explain why not. Ross et al. (2002) stressed on the importance of identifying the limits of the LCA. Only Souchon et al. (2007) coupled uses and consumption to determine energy consumption of ICT networks in France taking into account the telecom infrastructure. They showed that the energy used by the infrastructure should not be ignored and that realistic use scenarios were important.

\subsection{New Hot-Spots of a System Based on M2M}

As the name suggests, a PSS is a system. Correctly conducted, there is no reason that an LCA undertaken to eco-design a product does not also cover the associated services. However for different practical reasons, such as the lack of reliable data linked to the necessity to project particular situations of use, approximations are often made during the LCA and care must be taken not to loose sight of the effects on the services. These effects may become even more important when we consider the system aspect. Literature can help identify some important points to help go beyond the simple enumeration of environmental hot-spots of the ICT components or products and begin ecodesign of the system.

\section{Multi-Criteria LCA}

Multi-criteria LCA are necessary to survey the possible transfer of impacts from one impact category to another. This is all the more important as the M2M PSS solution uses electronic products compared to more classical services that require, for example, additional transport. The two kinds of services do not affect the same impact categories in the same ways. For example, the electronic industry uses significant quantities of water and rare metal resources, while air pollution for transport is noteworthy. To facilitate comprehension and interpretation of the results a reduced number of pertinent impact categories should be highlighted. These categories must be carefully chosen according to the domains covered by the application.

\section{Telecom Infrastructures}

As pointed out above, it is necessary to correctly identify the limits of the study as well as the quality of data used. This point is particularly important when dealing with large, complex infrastructures like telecom infrastructures. The LCA must consider the complete system including the telecom infrastructures. They can be of two types: the classical telecom infrastructure covers the classical services of GSM communication and IP connection; while the particular PSS infrastructure is dedicated to the local sensor network and the associated equipment. The global telecom infrastructure is normally present before the introduction of the PSS, whereas the PSS infrastructure is constructed for the purposes of the application. Data on these infrastructures is rather scarce and incomplete today. This should not disqualify the important work on eco-design of M2M PSS, but the problem must be clearly conscripted and the boundaries justified in order to avoid misinterpretation of the results.

\section{Scenarios}

A comparison of the effects on the environment for different scenarios is needed to determine the best solutions. Environmental benefits procured by the M2M PSS should be compared to M2M impacts. In this way it is possible to check the trade-offs between electronics and transport, for example. A critical element of this comparison would concern the use-stage. In order to determine realistic scenarios of use for this stage, an extensive field-study with detailed field observation of the execution of the service can be necessary. This is especially true when the PSS solution has not yet been fully deployed. In this case it is difficult to correctly anticipate full-scale deployment and it is better to confront approximations with field observation when they are unavoidable.

Alternative scenarios should be used to confirm design choices not only compared to classical solutions but also for correct dimensioning of the M2M PSS solution. For example data rates should be varied to study their effects on the overall performance of the system and thus contribute to correct specification of the system.

\subsection{Eco-Design Perspectives}

Once the causes of environmental damage are pointed out, the major environmental impact contributors are identified to orientate discussions on eco-design. The results of the LCA are used to highlight influential parameters of the system and show how the organizations of the services affect the global environmental performance. Some parameters may be fixed in the application but others 
can be modified just because the right actors are addressed. For example, factors like electrical mixes in the countries concerned fall out of the scope of this paper while installation scenarios of additional equipment can be modified quite easily. Eco-design discussions are oriented to areas of interest where they can be effectively applied. Intelligent eco-design may, in turn, result in a shift in the important contributors and reveal new tracks for improvement. In addition, design parameters susceptible to alter the global impact must be studied to understand the true levels of influence of critical elements especially concerning the telecom infrastructure. Once again, new proposals will then be explored to improve the service. Important questions regarding the extent of mutualisation or the quality of information can also be tested. These concepts can contribute to more general understanding of challenges faced by M2M PSS today.

\section{Case Study and Environmental Impacts}

The methodology proposed is now applied to a case study of waste glass collection. The technical solution was tested in the Voiron County, France, in 2006 by Orange Labs.

\subsection{Waste Glass Collection in the Voiron County}

\section{The Conventional Scenario}

The Community of Agglomerations of the Voiron County (CAPV) manages a park of 200 waste banks with 400 containers collecting both clear and coloured types of waste glass. Glass collection from the banks mobilises one driver and his non-compacting, top-fill, crane-operated truck. It serves the 92,000 inhabitants in the County with two separate systematic weekly rounds. The first round covers a little over a hundred sites. In the second, there are almost as much, but the sites are sometimes further away. In each site there are two containers: for clear and dark glass, sometimes there is an extra container for clear glass. The collection of clear and dark glass must be done separately as the truck has only one receptacle. The round starts with clear glass. Only the containers that are over half-full are emptied. In the first pass for clear glass the driver indicates on a report sheet the containers that were emptied and whether or not the dark glass containers should be emptied. In this way he needs only go back to the dark glass containers requiring emptying. This point is very important for the use scenario studied further on in the paper.

\section{M2M-enhanced PSS Scenario}

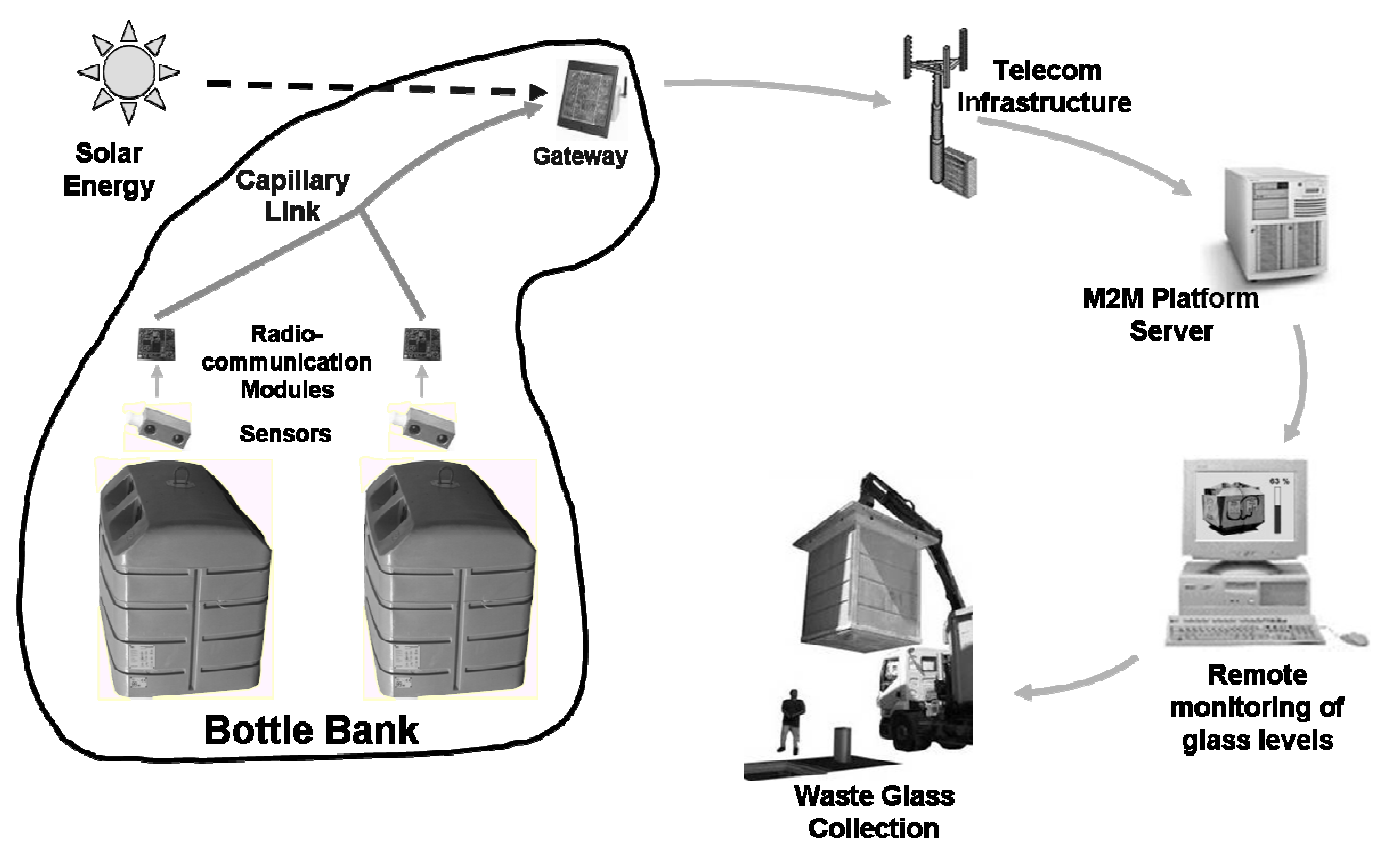

Figure 2: Basic principles of glass collection with the PSS

The M2M PSS is then added to the conventional glass collection scheme and provides information through a network of sensors placed in the waste bins. The basic principles are shown in figure 2. The sensors in each bin measure the glass-level once every day. A local capillary network collects the information and sends it to a gateway close-by. The network uses a low-power Wavenis radiofrequency protocol for communications. The gateway is solar powered and sends on the information through the global telecom infrastructure by GSM. The global telecom infrastructure then relays this information by internet to a specific M2M platform server. Here the information is 
aggregated with information from all the other bins in the park together with information on the truck. A service optimization program housed in the server then determines the bins that require emptying according to predetermined glass-level limits. The results will then be sent down to a PC in the technical service headquarters. The truck driver can thereby consult the system each day before going on his rounds. He no longer has to make systematic rounds and will only need to go to the bins that must be emptied, saving time and driving. Together with the CAPV, is was decided to choose a rather prudent scenario collecting only bins that are at least $75 \%$ full for reasonable first estimations of the improved service.

\subsection{Goal and Scope}

This section summarizes the main issues concerning the scope of the study, the inventory and the impact assessment.

\section{Goal}

The LCA seeks to identify the main contributors of environmental impacts and benefits of an M2M system for the optimization of waste glass collection. The LCA results should also be useful from an eco-design perspective of the system.

\section{Functional Unit}

The functional unit used for the LCA is collecting waste glass in the Voiron County during ten years.

\section{System Boundaries}

The following life cycle stages of the system have been considered: fabrication (including extraction and transportation of raw materials and production), transportation (from the suppliers), installation and use. The end-of-life stage was not considered for two main reasons: M2M systems are recent and no realistic end-of-life scenario is available today; consistent data sets concerning end-of-life are not available today in the LCA database used. Due to a lack of realistic information on maintenance, this phase has not been considered either.

\section{Inventory}

The study uses data from the experimentation conducted in 2006 by Orange Labs in Voiron. Although the experimentation was performed on a reduced scale, it is possible to imagine what a full-scale deployment would be. In this perspective the park would have 200 bottle banks with 400 bins, for coloured and clear glass. Each bin would be equipped with a sensor and 150 gateways would cover the park. The LCA distinguishes the different constituents of the PSS.

- In the bins, only the sensors are considered, whilst the bins, already present in the conventional service, are omitted. The sensors include fabrication, transportation and use of the electronic components, printed circuit boards, battery, casing, etc. Where there is no precise information available, fabrication of the components is assumed in China, shipped to and assembled in France. Dismantling and end-of-life is not considered.

- The PSS infrastructure includes the specific elements dedicated to the PSS. They include the gateways, the M2M platform server and the PC used to consult information. In the first part of the case study, this equipment is used only by the PSS application. In section 5 however, for ecodesign purposes, an alternative scenario of mutualising this equipment with other services is considered. The gateways include fabrication, transportation and use of the electronic components, printed circuit boards, photoelectric cells, accumulators, casing, etc. Where there is no precise information available, fabrication of the components is assumed in China, shipped to and assembled in France. For the server and PC, only the electrical power consumption taken from Williams (2004) and Socolof et al. (2001) is considered. Dismantling and end-of-life is not considered.

- The global telecom infrastructure provides the GSM and internet links to the different devices. No new specific equipment is supposed to be introduced into the existing telecom network and equipment is shared between all the applications existing in the network. Allocation of the energy necessary to run the PSS, including equipment for data transmission and the use of building facilities was obtained from Orange Labs based on Souchon (2008). Basically, energy used during the use phase in the Orange network in France was divided into running the facilities and actual communication. Then, depending on the role of the equipment, parts were allocated to fixed telephone, mobile telephone and/or internet. Finally the energy allocated to the particular communication involved in the case study was calculated according to the number and types of subscriptions concerned.

- The installation of the service is represented by train transport to Voiron and fuel consumption of the vehicle used to install the sensors and gateways. 
- Energy mixes corresponding to the countries concerned (France or China) have been used.

- Environmental benefits of the PSS result from the reduction of energy and material consumption to work the service. This includes fuel economies due to reduced distances covered by the pick-up truck during collection. These economies have been estimated from field observation for the PSS collection scenario. They are taken into account in section 5.1 .

LCA data has been extracted from the $\operatorname{EIME}^{\circledR}-10$ database (EIME, 2009) as this database is a reference in the electronic sector. A summary of the different elements of the PSS is presented in Table 1.

\begin{tabular}{|c|c|c|c|c|}
\hline \multirow{2}{*}{ Element } & \multirow{2}{*}{ Description } & \multicolumn{3}{|c|}{ Life Cycle Phase } \\
\hline & & Fabrication & Transportation & Use \\
\hline Sensor & Glass-level sensors in the bins & yes & yes & battery \\
\hline Gateway & Solar gateway & yes & yes & solar \\
\hline GSM & $\begin{array}{l}\text { M2M network } \Leftrightarrow \text { Telecom } \\
\text { network }\end{array}$ & $x$ & $x$ & $\begin{array}{l}\text { electricity grid } \\
\text { only }\end{array}$ \\
\hline Internet & $\begin{array}{l}\text { Telecom network } \Leftrightarrow \mathrm{M} 2 \mathrm{M} \\
\text { Platform }\end{array}$ & $x$ & $x$ & $\begin{array}{l}\text { electricity grid } \\
\text { only }\end{array}$ \\
\hline M2M Platform & Server, rack, air-conditioning & $\begin{array}{l}\text { electricity grid } \\
\text { only }\end{array}$ & yes & $\begin{array}{l}\text { electricity grid } \\
\text { only }\end{array}$ \\
\hline Internet & M2M Platform $\Leftrightarrow$ Collect service & $x$ & $x$ & $\begin{array}{l}\text { electricity grid } \\
\text { only }\end{array}$ \\
\hline $\mathrm{PC}$ & $\mathrm{PC}$ at the collect service & $\begin{array}{l}\text { electricity grid } \\
\text { only }\end{array}$ & yes & $\begin{array}{l}\text { electricity grid } \\
\text { only }\end{array}$ \\
\hline Installation & $\begin{array}{l}\text { Provider in Montpellier } \\
\text { Installation in the Voiron County }\end{array}$ & $x$ & yes & diesel \\
\hline $\begin{array}{l}\text { Environmental } \\
\text { Benefits }\end{array}$ & Fuel gains using the PSS & $x$ & $x$ & diesel \\
\hline
\end{tabular}

Table 1: PSS elements considered in the LCA.

\section{Life Cycle Impact Assessment Categories}

All the 11 indicators of environmental impacts available in the software EIME ${ }^{\circledR}$ were considered (EIME, 2009): Natural Resources Depletion (RMD), Energy Depletion (ED), Water Depletion (WD), Global Warming Potential (GWP), Stratospheric Ozone Depletion Potential (ODP), Air Toxicity Indicator (AT), Water Toxicity (WT), Photochemical Ozone Creation (POC), Air Acidification Potential (AA), Water Eutrophication (WE) and Hazardous Waste Production (HWP). However, in order to simplify the interpretation of results, this paper will only present a reduced number of indicators chosen according to Orange Labs' policy and their relevance in the context of M2M services. They are:

- ED (MJ): the energy contents in materials and the consumption of energy. It is an important parameter for running services.

- $\mathrm{GW}$ (g eq. $\mathrm{CO}_{2}$ ): the equivalent $\mathrm{CO}_{2}$ contribution to the greenhouse effect. This is a very important global issue today.

- AT $\left(\mathrm{m}^{3}\right)$ : the necessary volume of air to dilute contaminated air. This was chosen because it represents toxicity in a human environment. This is especially important for services deployed in the city.

- WT $\left(\mathrm{dm}^{3}\right)$ : the necessary volumes of water to dilute contaminated water. This was chosen because it represents toxicity in a human environment. This is especially important for services deployed in the city.

- RMD (year $\left.{ }^{-1}\right)$ : the depletion of natural resources, especially gold, silver and copper. These rare materials are used in electronic devices which are major components of M2M systems.

- HWP $(\mathrm{kg})$ : the quantity of hazardous waste produced for a given product. The electronic devices make use of batteries and accumulators that are considered hazardous according to European regulations.

These impact categories are typical for LCA of electrical and electronic devices. Sanitary impacts of electromagnetic waves are not considered in this study, as with noise pollution. 


\section{Identification of Limits}

Other than the limits derived from the quality of the data-base and their inherent incertitude, the limits in this paper are due mainly to the unavailability of data sources and lack of time. A full inventory of the equipment used in the telecom structures and the pick-up truck, including the fabrication stages is missing and should be included in future work. Truck-crane operation and then effects of enginerunning at halts during the rounds should also be considered. Installation was covered very briefly and maintenance and end-of-life stages should be included. In general, the results very much rely on the quality of data collection as well as use-scenarios. A real full scale application does not yet exist and even though the use scenario is based on field survey it should still be subject to caution.

\subsection{Results of the LCA Analysis}

\section{Major Contributions}

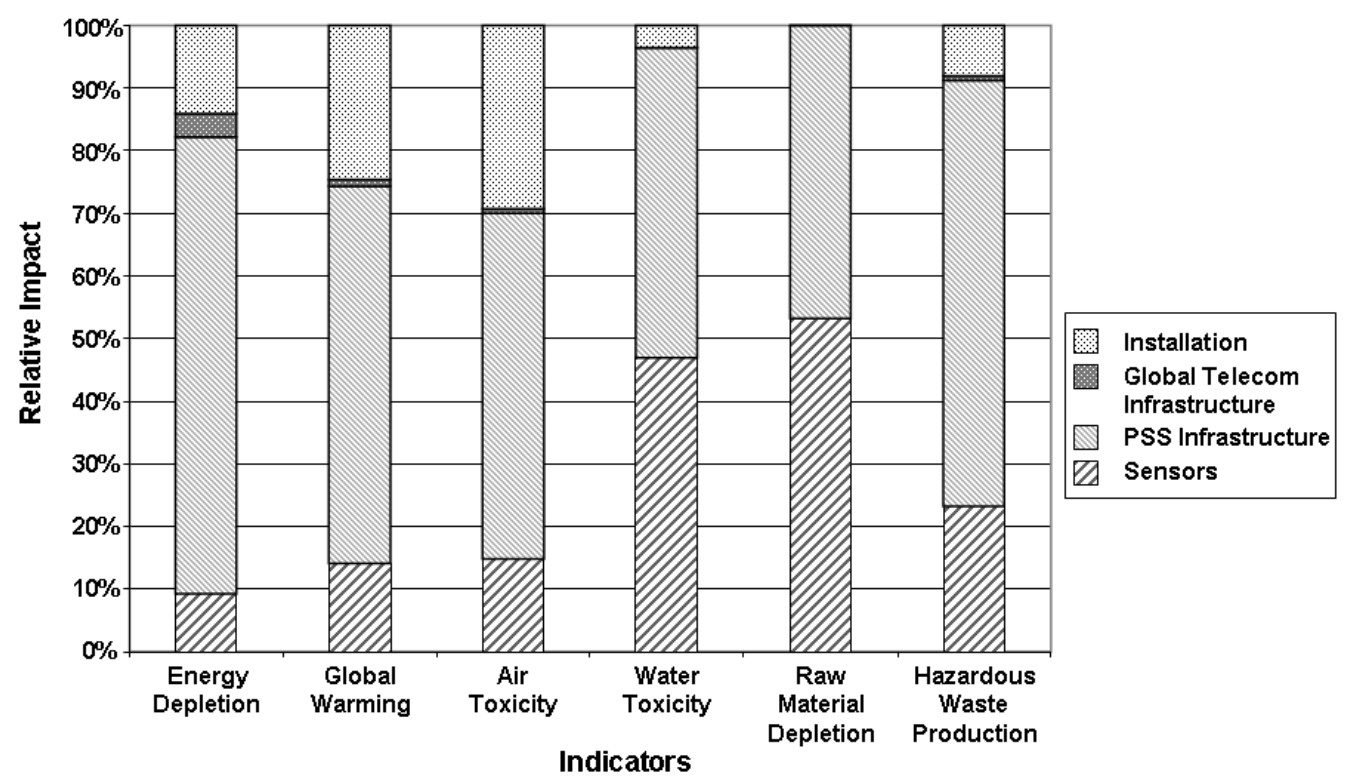

Figure 3: Environmental cost of the main PSS elements for daily communication

The relative impacts of the different elements of the system can be seen in figure 3 . The most important contributor is the PSS infrastructure with ED (73\%), HWP (68\%), GW (60\%), AT (55\%), WT $(50 \%)$ and RMD (47\%). It is followed by the sensors, which show the most important contribution to RMD (53\%) and are important for WT (47\%), HWP (23\%), AT (15\%) and GW (14\%). However, the installation of the service must not be neglected especially for AT (29\%), GW (25\%) and ED (14\%). The global telecom infrastructure does not show significant impacts (less than $4 \%$ ).

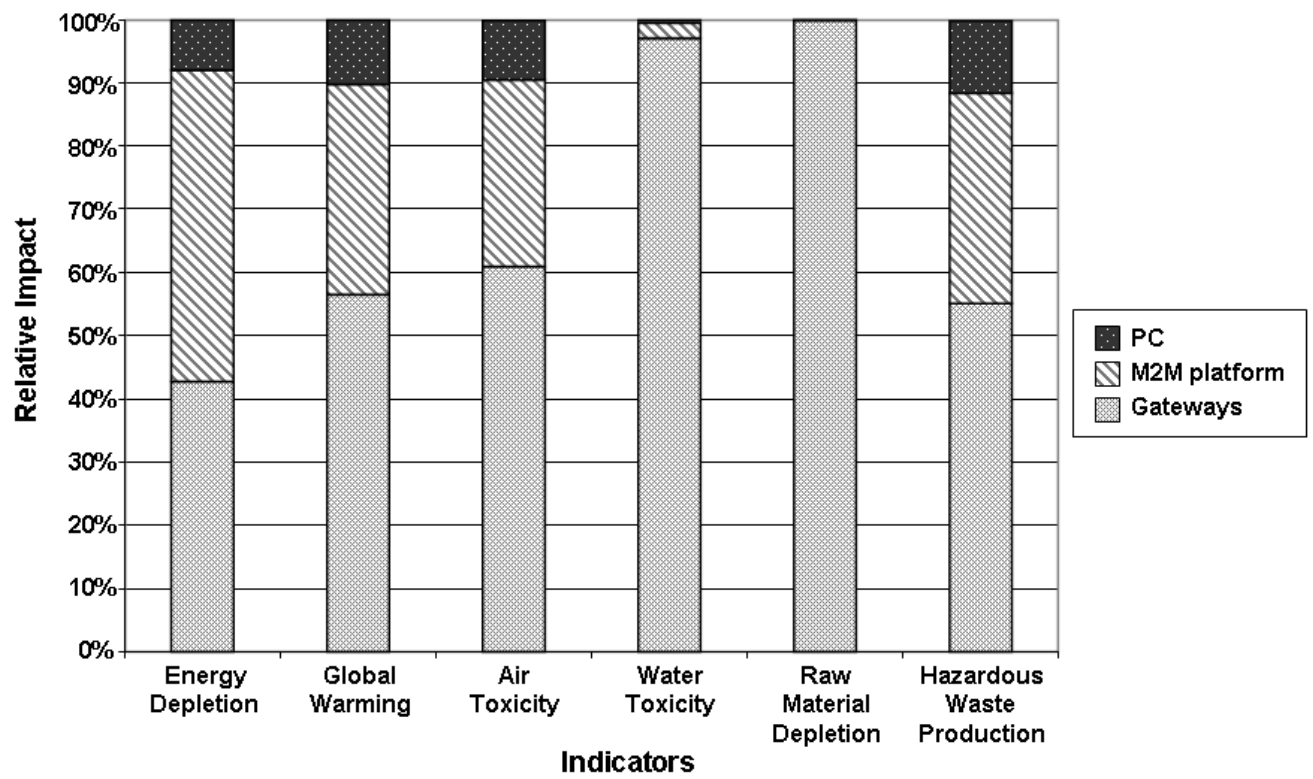

Figure 4: Relative importance of the elements of the PSS infrastructure 
A more detailed analysis of the PSS infrastructure is shown in figure 4. The gateways are the most impacting element for RMD (99.9\%), WT (97\%), AT (61\%), GW (56\%) and HWP $(55 \%)$ and the second for ED (43\%). The M2M platform accounts for $49 \%$ of ED and about $1 / 3$ of GW, HWP and AT. The PC used by the driver is a low contributor to the impacts.

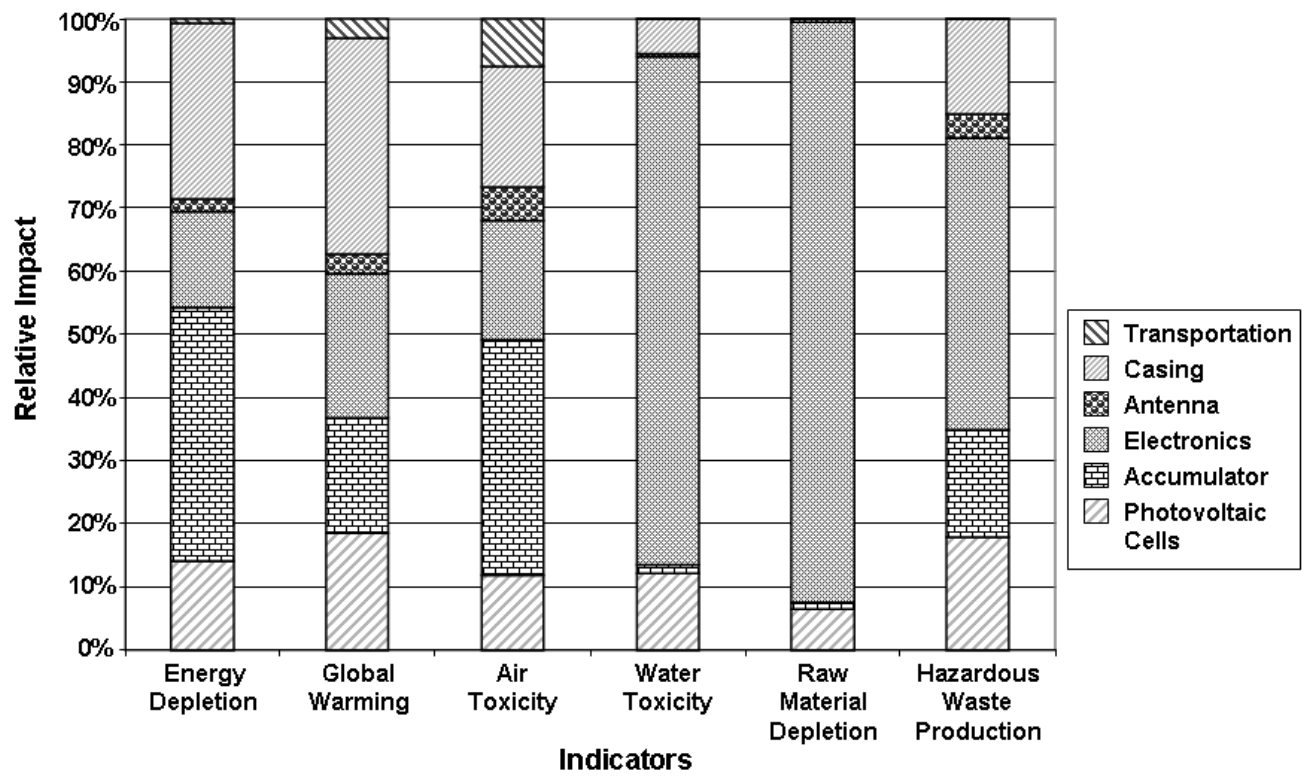

Figure 5: Relative importance of components of the gateway

Deeper investigation of the gateway (figure 5) shows the importance of the electronic components as the first contributor to RMD (92\%), WT (80\%) and HWP (46\%); the second to GW (23\%); and third to AT (19\%) and ED (15\%). The accumulators are the most important contributor for RMD (40\%) and AT (37\%), but also are important for GW (18\%) and HWP (17\%). The casing is the major contributor to GW $(23 \%)$ and second for ED $(28 \%)$ and AT (19\%). The photovoltaic cells are the second contributors to HWP (18\%), WT (12\%) and RMD (7\%), but have important contributions in all the other categories. The antenna and transportation have much lower contributions.

\section{Primary Conclusions}

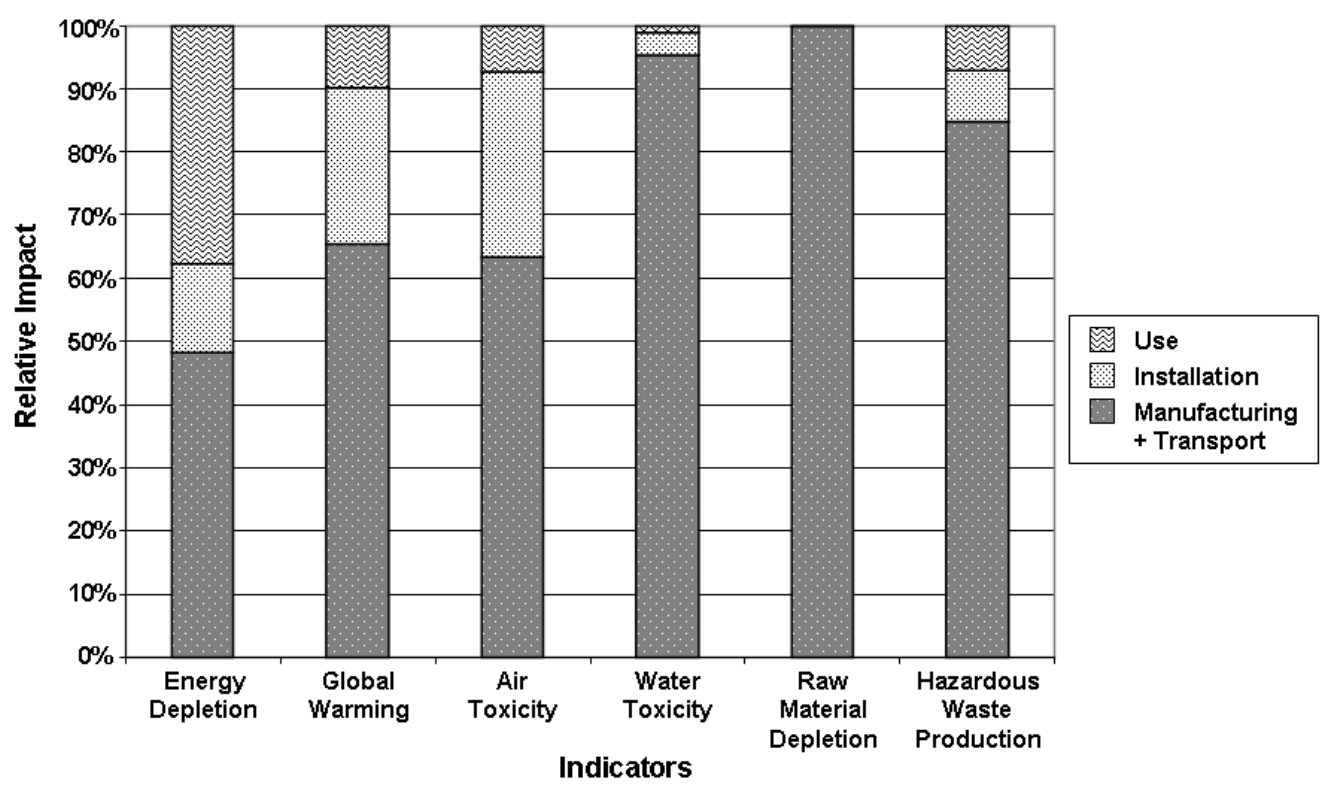

Figure 6: Contribution of each phase of the life cycle

Examination of the different life cycle stages shows the relative impacts of each phase (figure 6). The manufacturing phase is the most important for all the categories: RMD (99.9\%), WT (95\%), HWP (85\%), GW (65\%), AT (63\%) and ED (48\%). Installation accounts for AT (29\%), GW (25\%) and ED (14\%). The use phase is mainly visible in ED (37\%) and GW (10\%). 


\section{Conclusion on the Basic Contributions}

Primary analysis identifies the importance of the fabrication of the PSS infrastructure (gateways) and the sensors as contributors to environmental impacts. For these devices, the energy supply (accumulator and photovoltaic components) and the electronic components are the main contributors. Development or choice of equipment using more efficient technologies (smaller components, less impacting technologies) should decrease the overall impacts of the system. Mutualisation of the PSS infrastructure with other services could also be a solution to decrease the effects of fabrication of the PSS equipment.

The results also show that the contribution of the global telecom infrastructure is not important, tending to justify its negligence in most literature reports. However this point will be investigated more deeply further on.

Next, the work reveals the importance of the installation phase even though it only accounts for the fuel needed to set up the installation in the city and its surroundings. It suggests that logistics for installation is an important issue. The installation of the sensors in the bins can however be improved if the sensors are included in the fabrication of the bins. Although they have not been accounted for installation also reflects the potential influence of the maintenance, replacement and disposal stages as these stages also require going to the sensors and gateways. If the PSS is successful and spreads out to more and more cities, better organization of all these phases could become critical for service providers. Their impacts, if the network were, once again, to be mutualised with other PSS could be greatly improved with good coordination between the different actors.

In conclusion eco-design of the global M2M system should imply searching for cleaner technologies, better organization of installation, maintenance and dismantling, mutualisation and closely coordinated action between actors providing different services.

\section{Implications for Eco-Design}

\subsection{Environmental Benefits due to Reduced Energy Consumption}

\section{Benefits from Reduced Energy Consumption}

It is possible to compare the impacts of the M2M PSS with the benefits derived from reduced energy consumption. This is the result of fuel-saving from reduced truck-driving. Field observation of the conventional collection service was carried out. The driver was accompanied during his rounds both in the countryside and in denser city areas. Distances covered were noted and estimations on possible reductions were made supposing prior knowledge of the bins to be emptied. The reductions were estimated at $850 \mathrm{~km}$ per year in the Voiron County. Assuming 22 litres of diesel for $100 \mathrm{~km}$ for the truck, the avoided impacts due to fuel-saving can be compared to the impact of the PSS for different impact categories. The result is presented in Figure 7. The relative values of the PSS impact and the avoided impacts are shown, positive for the PSS impact and negative for the avoided impact or fuelsaving.

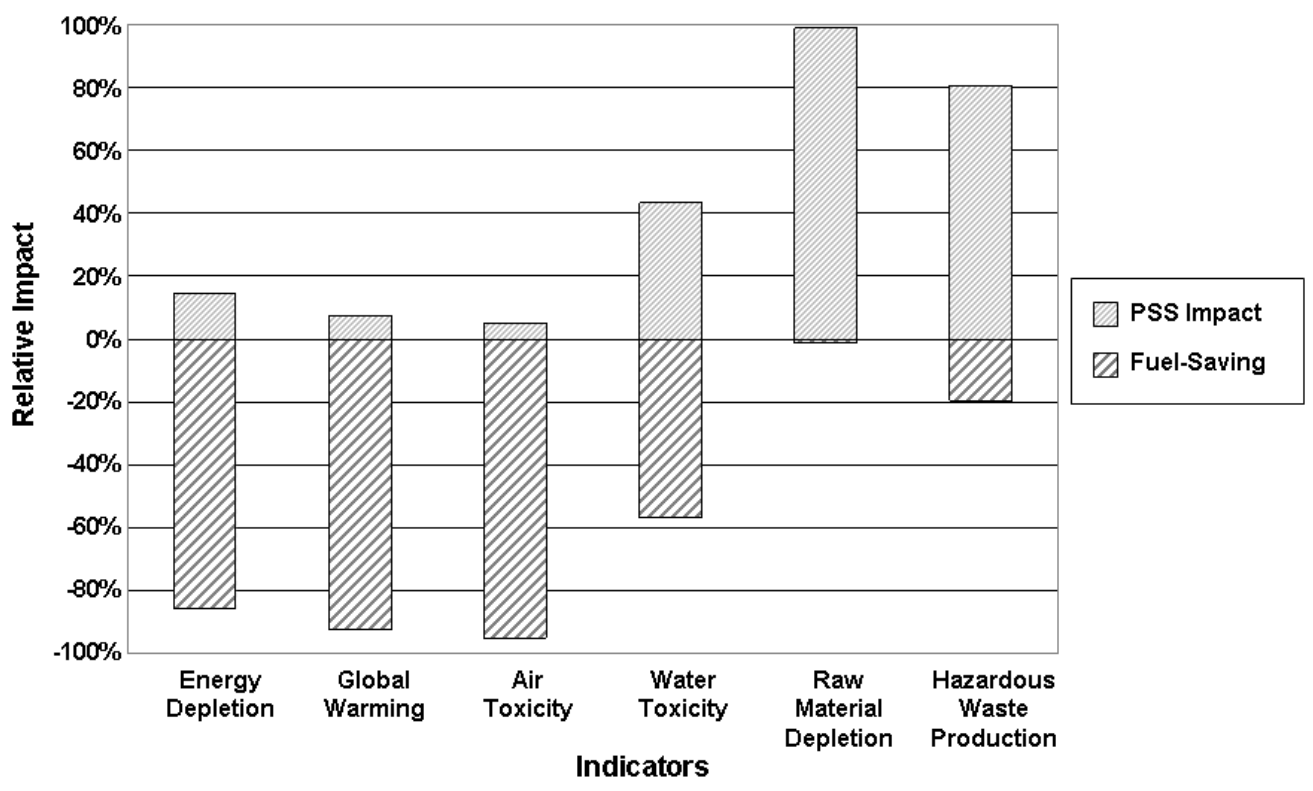

Figure 7: Ratio of environmental benefits from fuel-saving to the PSS impact 
Figure 6 displays the different impact categories. It shows that the PSS solution strongly improves the traditional solution in terms of AT (-90\%), GW (-84\%), ED (-72\%), impact categories strongly affected by truck transport. Benefits still exist for WT $(-6 \%)$. However, the PSS degrades RMD $(+98 \%)$ and HWP (+60\%) indicators, impact categories strongly affected by electronics.

\section{Discussion on Potential Benefits and Trade-offs}

Results suggest that waste glass collection can be improved with M2M PSS. Seeing that the pick-up trucks only go to bins that need to be emptied it is possible, for the same quantity of glass collected, to increase the number of waste banks without increasing the distances covered by the trucks and the road and noise disturbances associated with the glass collection. This will most likely encourage people to bring their waste glass to the banks. The major issues lie in the trade-offs between petrol and electronics. On one hand the conventional service resorts to trucks and driving using energy resources, essentially fuel, and strongly affects global warming and the quality of the air. On the other hand the proposed solution replaces this with electronics and telecommunications that consume precious metals and generate hazardous waste. The importance of using multi-criteria LCA for analysing environmental performances of M2M-enhanced solutions is illustrated by this result. Its consequences are important for decision-makers as in the case of local authorities who have to choose between different waste management scenarios. They need to understand that although electronics have the potential to decrease impacts such as global warming, they will also cause other impacts. If the M2M solution is finally adopted, then, in order to release the burden on the environment it is necessary to ensure correct collection and dismantlement of the electronic equipment and efficient recycling of materials, in particular to retrieve precious metals. In this way the RMD impact can be strongly reduced.

\subsection{Influence of the Quantity of Data Transmitted LCA for Different Quantities of Data}

An important design parameter of the PSS studied in this paper concerns the very low daily data transfer rate. The application could have required better Quality of Service (QoS) to reduce the danger of overflowing bins that are very bad for the image of the local council and for the security of the users. In this case we could examine the effects of increasing the number of daily emissions to 24 (hourly instead of daily emissions). To do this the power capacity of both the sensors and the gateways must be scaled to deal with increased data rates. The size of the photovoltaic cells and the accumulators of the gateways must be scaled up to relay 24 times more information. Also the size of their casing must be increased to accommodate the accumulators. Likewise for the sensors, the batteries and the casing must be increased. As can be expected, figure 8 illustrates a greater environmental impact when increasing the number of emissions per day.

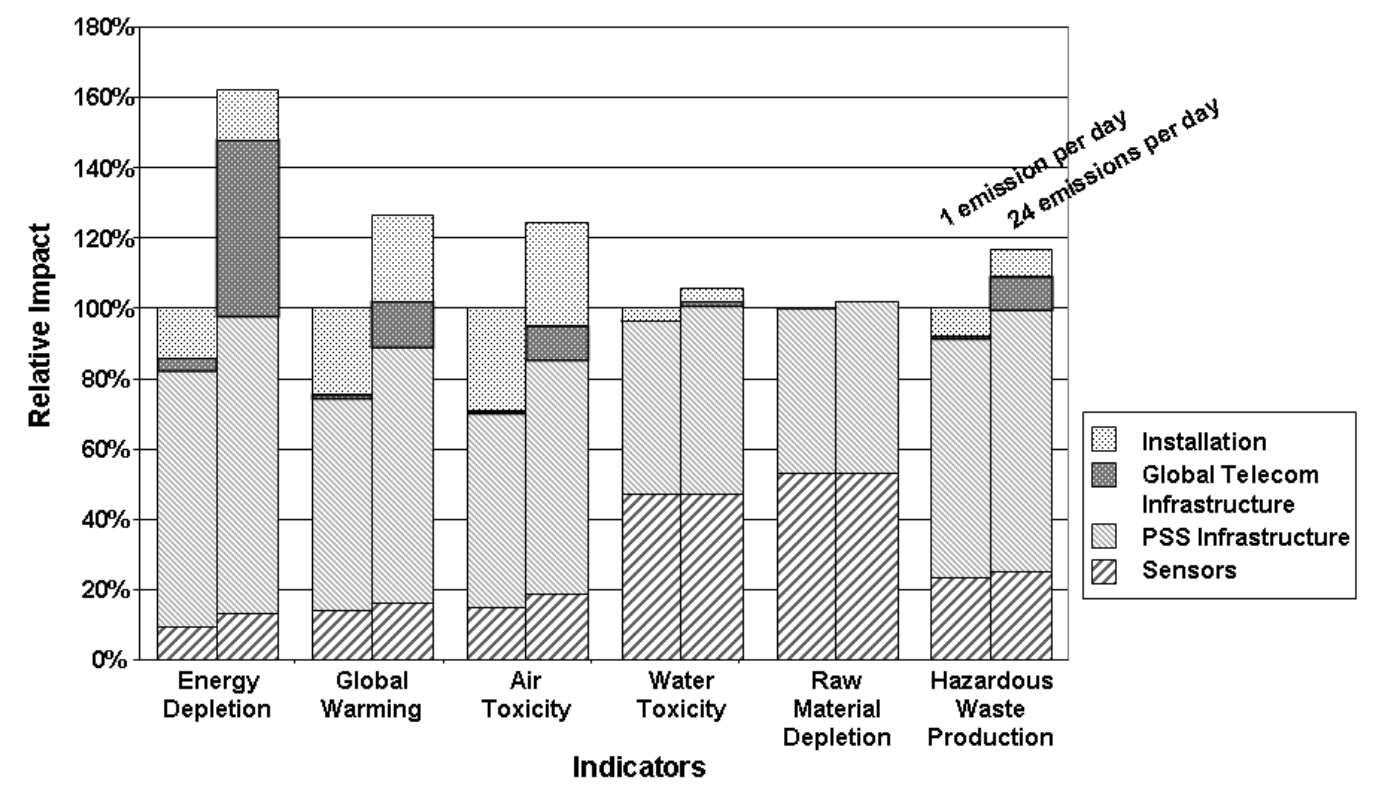

Figure 8: Effect of increasing to 24 emissions per day

The case of daily emission is taken as the reference for $100 \%$. The effect of increasing the data transmission rate is seen by the relative increase in all the impact categories. The most important increases are seen in ED (+62\%), GW (+27\%), AT (+24\%) and HWP (+17\%). However the effects 
both on the absolute and relative impacts of the global telecom infrastructure are notable. From a very low level in the case of daily emissions, the telecom infrastructure becomes the second contributor to ED with $31 \%$ of total impact, and to a lesser extent to GW (10\%), HWP (8\%) and AT (8\%).

\section{Quantity of Data Exchanged}

Although the influence of the telecom infrastructure was low in the study presented, this can change very quickly if larger data quantities are exchanged, as would be the case with many other M2M services. It is not possible a priori to neglect the telecom infrastructure as is often done in the reported literature. It is also important right from the preliminary or design phases to correctly dimension the needs for data. Data can for example be measured and sent weekly, daily, hourly or at any other rate and this will largely influence the use phase, the dimensions of the gateways and sensors, as well as maintenance frequencies. It is therefore very important to correctly dimension data requirements and this from early eco-design stages. The same goes for the quantity of information and the communication protocols. As for the influence of the global telecom infrastructure, the results suggest that the GSM has a greater impact than the internet. The choice of GSM, easy to install and requiring no wiring, could be reconsidered, especially when the gateways are placed in the proximity of existing telephone poles or electric lines. This could also help resolve power supply problems, but in that case the solar solution needs to be compared with the electricity supply grid.

\subsection{Mutualisation of the PSS Infrastructure between Different Services}

\section{LCA with a Mutualised Infrastructure}

Another important design parameter concerns the number of services associated with the PSS infrastructure. Figure 3 showed that the PSS infrastructure plays the most important role in the environmental impacts. It would be important to reduce this contribution in order to globally improve the PSS. If we take a wider view on the type of service provided by the PSS, we note that the service covers urban settings. Other M2M services cover the same areas. We can cite some environmentallyoriented applications currently found or experimented in modern towns like monitoring of street lightning, pollution measures or monitoring of water meters. All these services could use the same PSS infrastructure (Lelah et al., 2010) and therefore possibly reduce the environmental impact of each service. Although no other service was associated with the Voiron PSS infrastructure, a simple hypothesis can be used to gain insight to the benefits that could be expected. To do this most conveniently, we could extend the results obtained with 24 measures a day and instead imagine that 24 similar services work on the same network. That means that if we look only at our initial PSS we would find the same sensors and global telecom infrastructure, whilst parts of the PSS infrastructure, particularly the gateways, would be mutualised. As in the case of 24 measures a day we need to increase the power supply of the gateways, but this time we can allocate 1/24 of the gateways' impact to each service separately. In addition, to manage the system we will suppose that we need to add a new server to the M2M platform to deal with mutualisation, and that its' impacts must be shared between the 24 applications. We will assume however that no mutualisation of the installation is done.

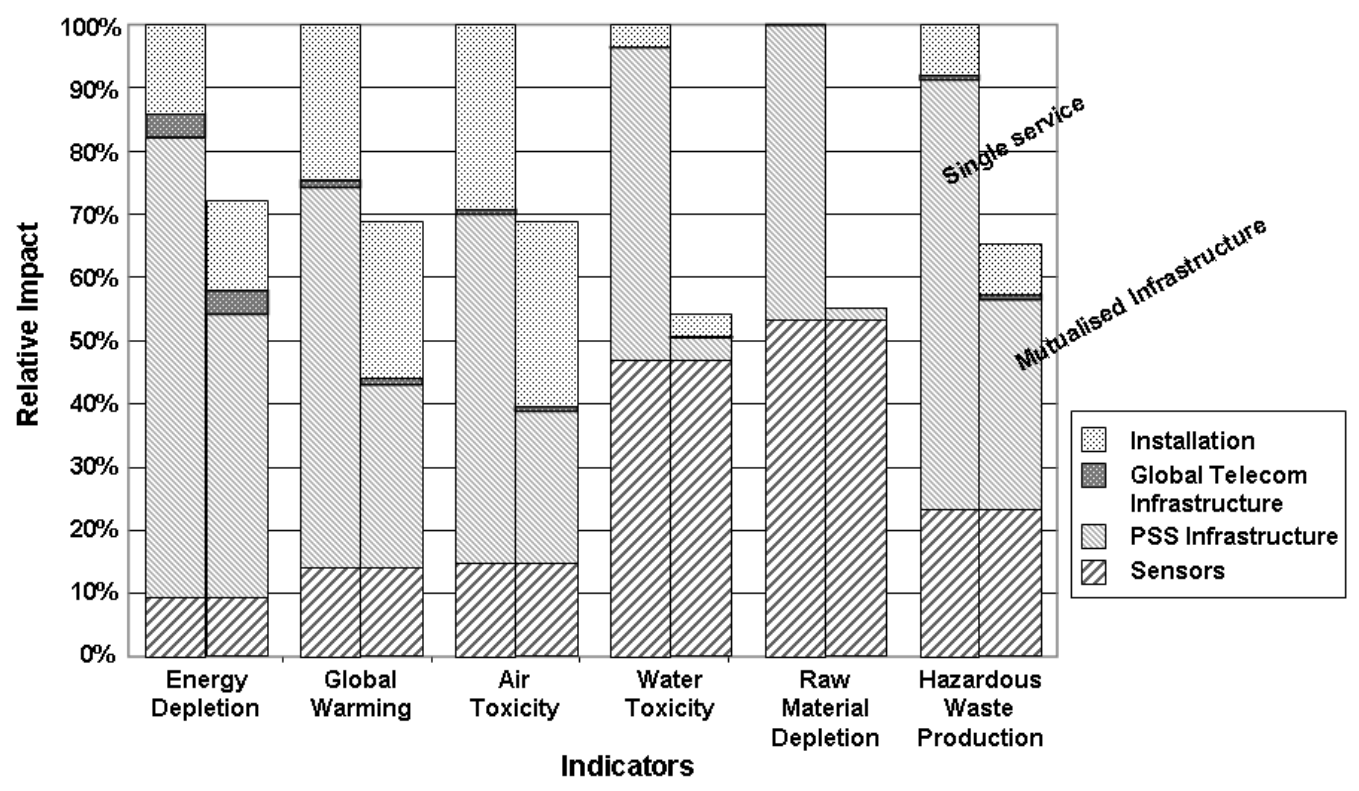

Figure 9: Effect of mutualising 24 services with one common PSS infrastructure 
The results of this scenario for our PSS are shown in figure 9 comparing the new results with a mutualised infrastructure to that of the old single service.

Our single PSS studied in the first part of this paper has an impact of $100 \%$ for each category. The corresponding impact of the PSS in a mutualised PSS infrastructure is displayed next to it. The reduction of all impacts is dramatic: WT $(-54 \%)$, RMD (-45\%), HWP $(-35 \%)$, GW $(-31 \%)$, AT $(-31 \%)$ and ED (-28\%). However the relative importance of the installation and the global telecom infrastructure increase notably. The relative part of the installation becomes the greatest contributor to AT $(43 \%)$ and is important for GW (36\%), ED (20\%) and HWP (12\%). The telecom infrastructure increases to $5 \%$ of the global impact for ED.

\section{Discussion on the Mutualisation of the PSS Infrastructure}

The PSS infrastructure is specific for the PSS and is preponderant in environmental considerations. This is verified concerning energy flows in the use phase and, for certain devices, also in the fabrication phase. The result would most probably hold if material and other process flows were accounted for seeing that most of the devices concerned are equivalent electronic products. The study suggests one possible means of reducing the burden of the PSS infrastructure through mutualisation.

\section{PSS and Environment}

The PSS studied should be positioned on the 8-level grid proposed by Tukker (2004). There is little doubt that the system proposed globally aims at replacing materials (reduced use of the truck and fuel economies) with a service (gathering information to instruct pick-up routes). However the details are a bit trickier to understand. To simplify things we can distinguish three major elements within the collection system: the bins, the M2M network and the pick-up truck. The bins and the truck are owned by the local council and therefore must be considered as pure products and not PSS. However the M2M provider will install the M2M network, operate it and plan the collection of glass from the bins. The M2M equipment, maintenance, operation and upgrading all belong to, or are the responsibility of, the M2M provider and only intangible services are supplied to the local council. For this part of the final service rendered to the citizens we are clearly dealing with the final level of a PSS based on functional results. The functionality includes the intangible knowledge of the state of the bins and day to day planning of collection rounds along with the tangible physical components comprising the network. According to Tukker (2004) this level provides the best opportunities for environmental benefits. Nevertheless this only applies to the M2M network itself. There is no reason that the system either improves the life-span of the bins or reduces the amount of materials used for their construction. No environmental gains are expected in this area. However, on the global system level, knowledge obtained through the M2M network will help reduce the need for truck-operation and fuelconsumption. Indeed, our PSS aims to improve the conventional collection service by providing information that would avoid sending the truck to unnecessary bins. We are clearly in the case of information-based eco-services identified by Bartolomeo et al. (2003) that "focus on changing user practices through better knowledge, but can also have implications for both devices and infrastructure".

In conclusion, we may consider that our example concerns an M2M PSS within the limits described above and we can foresee the areas where benefits should be reaped.

\section{Conclusions and Further Work}

Methodology based on LCA adapted to the M2M PSS context and contributing to eco-design has been presented. It stresses on multi-criteria LCA with identified boundaries covering the telecom infrastructures and based on realistic data projections collected from field survey. The LCA is tested in various organizational configurations chosen because of their potential to lead to interesting ecodesign proposals. The proposed methodology was effectively employed and validated on a waste glass collection service tested by Orange Labs in a French city. The case study demonstrated the necessity to cover the complete system, including the global telecom and the local PSS infrastructure. Key system-design technical parameters going from energy-supply technology to the quantity of data transferred were identified as having important influences on the overall environmental performances. The case study also revealed the environmental importance of business and organizational parameters such as the mutualisation of the infrastructure and installation / maintenance / disposal procedures. It shows the importance of correctly specifying data requirements. Proposals for ecodesign of the system could therefore be made. The work in this paper represents a step towards a better understanding of concepts influencing the environmental performances of M2M PSS. Through a case study, it interrogates some of the questions posed today dealing with M2M PSS and its 
associated infrastructure. The concepts could potentially be extended to other examples in the domain. In this respect, the study showed that M2M PSS has the potential to achieve environmental benefits and contribute to improving waste glass management and other PSS. The methodology gives insight on critical choices and enhances eco-design the system. However it also suggests that although they show potential for some improvements, functional PSS may not automatically be a guarantee for radical environmental gains.

The conclusions of this work are a starting point for deeper investigations. We have seen that the environmental effects of PSS resorting to high technologies can be promising. However they have a cost and it is necessary to characterise their impact based on plausible usage scenarios. Further work should examine other M2M PSS cases to check whether the same conclusions leading to organized infrastructures and mutualised networks still hold. It should also consider more advanced prototypes or cases of wide-scale implantations with fully commercialized services.

\section{Acknowledgements}

The authors would like to thank Orange Labs for access to their data as well as the CAPV for their support in the experimentation.

\section{References}

ADEME (Agence de l'Environnement et de la Maîtrise de l'Energie) (2009) Waste figures for France, $<w w w 2$.ademe.fr/servlet/getDoc?sort=-1\&cid=96\&m=3\&id=63736\&ref=\&nocache $=$ yes \&p1=111> accessed on 06/10/2010

EIME (Environmental Improvement Made Easy) (2009). EIME Indicators Manual, $<$ www.codde.fr/files/EIME\%20Manuel\%20Indicateurs_Juillet_09_CODDE_BV.pdf> accessed on $06 / 10 / 2010$

FEVE (The European Glass Container Federation)

$<w w w$. feve.org/index.php?option=com_content\&view=article\&id=10\&ltemid=11 >, accessed on 06/10/2010

Baines, T. S., Lightfoot, H. W., Evans, S., Neely, A., Greenough, R., Peppard, J., Roy, R., Shehab, E., Braganza, A., Tiwari, A., Alcock, J. R., Angus, J. P., Bastl, M., Cousens, A., Irving, P., Johnson, M., Kingston, J., Lockett, H., Martinez, V., Michele, P., Tranfield, D., Walton, I. M., and Wilson, H. (2007). State-of-the-art in product-service systems. Proceedings of the Institution of Mechanical Engineers, Part B: Journal of Engineering Manufacture, 221(10), 1543-1552.

Bartolomeo, M., dal Maso, D., de Jong, P., Eder, P., Groenewegen, P., Hopkinson, P., James, P., Nijhuis, L., Örninge, M., Scholl, G., Slob, A., Zaring, O. (2003). Eco-efficient producer services--what are they, how do they benefit customers and the environment and how likely are they to develop and be extensively utilised? Journal of Cleaner Production, 11(8), 829-837.

Bjarnadóttir, H. J., Friðriksson, G. B., Johnsen, T., and Sletsen, H. (2002). Guidelines for the use of LCA in the waste management sector. Published by Nordtest, Tekniikantie 12, FIN-02150, Espoo

Finland.

Bonneau, V. (2005). Strong Growth of Wireless M2M and Impact of RFID. M36105-2005 Edition IDATE DigiWorld.

Bouzon, J.M. (2005) Personal Communication of the Responsible of Collection and Recycling Services of the Community of Agglomerations of the Voiron County (CAPV), France Bovea, M., Ibáñez-Forés, V., Gallardo, A., and Colomer-Mendoza, F. (2010). Environmental assessment of alternative municipal solid waste management strategies. A Spanish case study. Waste Management, 30(11), 2383-2395.

Carrillo-Hermosilla, J., del Río, P., and Könnölä, T. (2010). Diversity of eco-innovations: Reflections from selected case studies. Journal of Cleaner Production, 18(10-11), 1073-1083.

DCCSVMF (Glass Syndicate of France) <www.verre-avenir.fr/accueil/le-recyclage-du-verre-a-35-ans> (in French), accessed 06/10/2010

Dubberley, M., Agogino, A., and Horvath, A. (2004). Life-cycle assessment of an intelligent lighting system using a distributed wireless Mote network (p. 122-127). IEEE International Symposium on Electronics and the Environment, Scottsdale, AZ, USA.

Edwards, D., and Schelling, J. (1999). Municipal Waste Life Cycle Assessment: Part 2: Transport Analysis and Glass Case Study. Process Safety and Environmental Protection, 77(5), 259-274. European Council. (2008). Directive 2008/98/EC of the European Parlement and of the Council of 19 November 2008. 
Goedkoop, M., Van Halen, J., Te Riele, H., and Rommens, P. (1999). Product Service Systems: Ecological and Economic Basics. Report for the Dutch ministries of Environment (VROM) and Economic Affairs (EZ).

Gold, S. and Seuring, S. (2011). Supply chain and logistics issues of bio-energy production. Journal of Cleaner Production, 19(1), 32-42.

González-Torre, P. L., Adenso-Díaz, B., and Ruiz-Torres, A. (2003). Some comparative factors regarding recycling collection systems in regions of the USA and Europe. Journal of Environmental Management, 69(2), 129-138.

Ijomah, W. L., McMahon, C. A., Hammond, G. P., and Newman, S. T. (2007). Development of design for remanufacturing guidelines to support sustainable manufacturing. Robotics and ComputerIntegrated Manufacturing, 23(6), 712-719.

Johansson, O. M. (2006). The effect of dynamic scheduling and routing in a solid waste management system. Waste Management, 26(8), 875-885.

Kriwet, A., Zussman, E., and Seliger, G. (1995). Systematic integration of design-for-recycling into product design. International Journal of Production Economics, 38(1), 15-22.

Lelah, A., Mathieux, F., Brissaud, D., and Gimeno, V., (2010). SensCity: a new project opening the way for sustainable services in the city based on a mutualised M2M infrastructure. Proceedings of the $2^{\text {nd }}$ CIRP IPS² Conference, Linköping, 99-106.

Lawton, G. (2004). Machine-to-machine technology gears up for growth. Computer, 37(9), 12-15. Lo, K. (1998). Design for reuse. IEE Colloquium on Systems on a Chip (Ref. No. 1998/439).

Loerincik, Y., Sangwon Suh, and Jolliet, O. (2003). Life cycle environmental impact of the Internet infrastructure in a university (p. 173-176). IEEE International Symposium on Electronics and the Environment, Boston, MA, USA.

Maussang, N., Zwolinski, P., and Brissaud, D. (2009). Product-service system design methodology: from the PSS - architecture design to the products specifications. Journal of Engineering Design, 20(4), 349.

McAloone, T. C., and Andreasen, M. M. (2002). Defining product service systems. Meerkamm (editor): Design for X, Beiträge zum, 13, Symposium, Neukirchen, 10-11. October 2002. Lehrstuhl für Konstruktionstechnik, TU Erlangen, 51-60..

Moberg, Å., Johansson, M., Finnveden, G., Jonsson, A. (2010). Printed and tablet e-paper newspaper from an environmental perspective - A screening life cycle assessment. Environmental Impact Assessment Review, 30(3), 177-191.

Mont, O. K. (2002). Clarifying the concept of product-service system. Journal of Cleaner Production, 10(3), 237-245.

Nakamura, J., Tsuda, M., Ichino Takahashi, K., Nishi, S., Takaoka, M. (2006). Analysis of the Potential Contribution of ICT Services to a Sustainable Society. Dans Proceedings of the 2006 IEEE International Symposium on Electronics and the Environment (p. 179-182).

Pennington, D. W., Potting, J., Finnveden, G., Lindeijer, E., Jolliet, O., Rydberg, T., and Rebitzer, G. (2004). Life cycle assessment Part 2: Current impact assessment practice. Environment International, 30(5), 721-739.

Plepys, A. (2002). The grey side of ICT. Environmental Impact Assessment Review, 22(5), 509-523. Reap, J., Roman, F., Duncan, S., and Bras, B. (2008). A survey of unresolved problems in life cycle assessment. The International Journal of Life Cycle Assessment, 13(4), 290-300.

Rebitzer, G., Ekvall, T., Frischknecht, R., Hunkeler, D., Norris, G., Rydberg, T., Schmidt, W., Suh, S., Weidema, B.P., Pennington D.W. (2004). Life cycle assessment: Part 1: Framework, goal and scope definition, inventory analysis, and applications. Environment International, 30(5), 701-720. Ross, S., Evans, D., and Webber, M. (2002). How LCA studies deal with uncertainty. The International Journal of Life Cycle Assessment, 7(1), 47-52.

Rovetta, A., Xiumin, F., Vicentini, F., Minghua, Z., Giusti, A., and Qichang, H. (2009). Early detection and evaluation of waste through sensorized containers for a collection monitoring application. Waste Management, 29(12), 2939-2949.

Seadon, J. K. (2010). Sustainable waste management systems. Journal of Cleaner Production, 18(1617), 1639-1651.

Socolof, M., Overly, J., Kincaid, L., Dhingra, R., Singh, D., and Hart, K. (2001). Life-cycle 
environmental impacts of CRT and LCD desktop monitors. Proceedings of the 2001 IEEE International Symposium on Electronics and the Environment. (p. 119-127). Denver, CO, USA. Souchon, L., Aebischer, B., Roturier, J., and Flipo, F. (2007). Infrastructure of the information society and its energy demand.

Souchon, L. (2008) TIC et Énergétique: Techniques d'estimation de consommation sur la hauteur, la structure et l'évolution de l'impact des TIC en France. PhD thesis at the Institut National des Telecommunications, (in French)

Taiariol, F., Fea, P., Papuzza, C., and Ramella, A. (2001). Environmental impact of a telecommunication service. Proceedings of the 2001 IEEE International Symposium on Electronics and the Environment (p. 273-278). Denver, CO, USA.

Takahashi, K., Tatemichi, H., Tanaka, T., Nishi, S., and Kunioka, T. (2004). Environmental impact of information and communication technologies including rebound effects. IEEE International Symposium on Electronics and the Environment. Conference Record. (p. 13-16). Scottsdale, AZ, USA.

Tasaki, T., Hashimoto, S., and Moriguchi, Y. (2006). A quantitative method to evaluate the level of material use in lease/reuse systems of electrical and electronic equipment. Journal of Cleaner Production, 14(17), 1519-1528.

Tukker, A. (2004). Eight types of product-service system: eight ways to sustainability? Experiences from SusProNet. Business strategy and the environment, 13(4), 246-260.

Tukker, A., and Tischner, U. (2006). Product-services as a research field: past, present and future. Reflections from a decade of research. Journal of Cleaner Production, 14(17), 1552-1556.

Williams, E. (2004). Revisiting energy used to manufacture a desktop computer: hybrid analysis combining process and economic input-output methods (p. 80-85). IEEE International Symposium on Electronics and the Environment, Scottsdale, AZ, USA. 